\title{
O conflito social No ChILE: ESTADO, MERCADO E DEMOCRACIA*
}

\author{
Social conflict in Chile: State, Market and democracy
}

\author{
Carlos Ruiz Encina ${ }^{a}$
}

Resumo A recente conflitualidade social e política no Chile se vincula ao esgotamento dos limites da política estabelecida pelo pacto da transição para a democracia. A expansão contínua dos processos de privatização das condições da reprodução social acabou por criar uma situação de aguda incerteza na vida cotidiana de amplos setores da sociedade, os quais, apesar do crescimento econômico, enfrentam uma grande desigualdade, derivada da extrema concentração econômica e de oportunidades. Os limites do sistema político e da até então bem-sucedida coalizão de governo são transbordados por um mal-estar que abriga a formação de novos atores sociais e políticos. Isso configura a possibilidade de uma passagem para um novo período político.

Palavras-chave conflito social; neoliberalismo; democracia; novos atores; Chile.

Abstract The recent social and political unrest in Chile relates to the exhaustion of the political boundaries established during the democratic transition. The continuous expansion of the privatization processes over the conditions for social reproduction, has created a situation of high uncertainty over the every day life of vast portions of society which, despite the economic growth, have to face a strong inequality, produced by extreme economic concentration and lack of opportunities. The boundaries of the political system - and the so far successful governing coalition - are overwhelmed by a social unrest which shelters the formation of new social and political actors. This bears the possibility of a transition to a new political period.

Keywords social conflict; neoliberalism; democracy; new political actors; Chile.

* Artigo traduzido do original, El conflicto social en Chile: Estado, mercado y democracia, por Andrea Soledad Roca Vera, doutoranda em Sociologia pela Universidade de São Paulo (USP).

a Sociólogo e doutor em Estudos Latinoamericanos. Diretor do Departamento de Sociologia da Universidade do Chile e presidente da Fundación Nodo XXI. 


\section{INTRODUÇÃO}

Nos últimos anos, a irrupção da conflitualidade social arrasou com a calma que caracterizava o cenário chileno, de forma um pouco contrastante com a experiência latino-americana das décadas anteriores. O que aconteceu? De onde surgiu essa mudança que parece ter vindo do nada? A recente conflitualidade social na sociedade chilena se vincula, intimamente, às excepcionais condições da refundação capitalista nesse país e, de modo concomitante, às restrições da transição para a democracia, assim como às dificuldades do processamento institucional de conflitos e interesses sociais que ocorrem sob o marco conservador dominante. De tal modo, não é possível uma compreensão de seu caráter atual, sem revisar, à guisa de antecedentes, aqueles elementos que emanam do passado imediato $\mathrm{e}$ que, agora, parecem explodir de forma inesperada.

Em primeiro lugar, atenta-se às transformações das condições de reprodução social, mormente no que se refere à aguda privatização e à mercantilização, assim como as mudanças na estrutura dos grupos e das classes sociais. Em segundo lugar, tem-se a precária capacidade para lidar com os novos dilemas sociais derivados desse capitalismo refundado, além da incapacidade das instituições políticas própria de uma ainda insuficiente abertura democrática -, junto ao desborde da política institucional por conta das atuais revoltas sociais.

A partir desses elementos, configura-se uma severa crise de legitimidade que afeta toda a esfera dessa política concebida no processo de transição elitista para a democracia. Trata-se de uma crise que instala necessidades urgentes de refundação do sistema político - aliás, do próprio caráter social da política -, a partir dessa recente conflitualidade social no Chile.

\section{ALGUMAS CHAVES DA REFUNDAÇÃO CAPITALISTA NO CHILE}

No Chile, a virada neoliberal apresenta um caráter pioneiro e até icônico, não apenas por sua origem prematura, abrupta e radical, mas também por certos alcances que, em seu desenvolvimento ininterrupto, alteraram profundamente as condições de reprodução de amplos setores da sociedade. Tal processo, ocorrido com bastante intensidade ao longo de mais de quatro décadas, torna-o uma experiência difícil de ser comparada, seja pelo grau de maturidade social e cultural que exibe, seja por conta dessa temporalidade que conformou um cenário sociocultural novo, em que é difícil reconhecer muitos dos vestígios da antiga sociedade chilena - dos tempos do desenvolvimentismo. Com efeito, o caso chileno resulta 
singular perante o resto da região latino-americana, onde ainda sobrevivem características tradicionais de grupos e forças sociais misturadas, de forma complexa, com elementos próprios da virada neoliberal nos níveis econômico, institucional, social e cultural.

A partir de 1975, logo após alguns conflitos iniciais - e com os resquícios ainda fumegantes do golpe militar -, consolidou-se a substituição dos chamados "neodesenvolvimentistas" pelos "Chicago Boys”. Nessa nova configuração, inicia-se uma transformação profunda, abrupta e carente de oposição social e política efetiva, em que se observam dois elementos: junto à já conhecida repressão dos velhos atores sociais subalternos do período anterior - como a classe operária e os setores médios desenvolvimentistas -, soma-se a debilidade histórica de um empresariado industrial que, à diferença das experiências no Brasil, Argentina ou México, não resiste à abertura indiscriminada, isto é, a financeirização e a desindustrialização impostas pelos preceitos monetaristas que animaram essa experiência inicial de refundação capitalista.

Trata-se de uma experiência excepcional de associação entre neoliberalismo e autoritarismo no Chile, que contrasta com uma América Latina onde tal transformação capitalista ocorreu nas democracias consolidadas dos anos 1990 - fato que ideologismos associados a certo progressismo neoliberal tendem a confundir, para assim ocultar o grau em que essas transformações foram, na realidade, implementadas sob as novas democracias, ao restringir, precisamente, seu caráter participativo e as possibilidades deliberativas (EnCINA, 2015).

Quer dizer, além das lutas ideológicas iniciais por meio das quais transcorre uma refundação das elites, foi somente nos governos de Menem, na Argentina, e Salinas de Gortari, no México, que esses preceitos se transformaram em orientações políticas concretas e determinantes dos modelos de desenvolvimento. Portanto, não são as ditaduras militares que, seja dito, afastaram-se sem ter resolvido os problemas para os quais foram invocadas - em especial, a refundação da ordem política e a própria resolução da crise desenvolvimentista -, ou seja, não foram elas que aceleram, de fato, o "fim da etapa fácil de substituição de importações".

Dessa época até então, transcorreram quarenta anos ininterruptos de experiência neoliberal no Chile e, com ela, uma mutação prolongada da sociedade, da estrutura de classes e dos grupos sociais, que terminaram por diluir as velhas bases sociais que sustentaram projetos políticos históricos, da política nacional-popular, desenvolvimentista e, em especial, a própria classe operária e as camadas médias. Paralelamente, decorre uma crise da esquerda histórica chilena e o impossível ajuste ao ideal social-democrata, invocado por governos mais neoliberais da 
Concertación, em busca de legitimação e identidade. É, portanto, o desmantelamento precoce da velha classe operária e da classe média desenvolvimentista que, no caso chileno, vinculava-se à expansão da centralidade do Estado na economia e na sociedade, desarticulação precoce e radical dos atores da etapa nacional-popular, isto é, daquela política característica do "Estado de Compromisso" que Weffort (1968) descrevera, do desenvolvimentismo enquanto "estilo de desenvolvimento". Trata-se, então, de uma transformação que perpassa todo o antigo cenário social chileno, de forma a desvendar, ao mesmo tempo, os marcos de uma nova sociedade, processo que, na atualidade, acaba por amadurecer, apresentando as condições da constituição da ação social, de atores e identidades, muito diferentes daquelas de outrora ${ }^{1}$.

A virada neoliberal no Chile reordenou o mapa dos grupos economicamente dominantes. O antigo cenário agrário da fazenda foi arrasado por uma "modernização" autoritária que introduziu reagrupamentos exportadores vinculados a novas alianças externas e ao assalariamento rural, que acabaram com o velho campesinato. A desindustrialização, por outro lado, consagrou a "perda do peso estratégico da classe trabalhadora”, e, em seu lugar, assistiu-se ao crescimento ininterrupto de trabalhadores do setor de serviços, cuja terceirização não responde sempre a simples ocupações precárias de refúgio, como mostrou a experiência nas décadas anteriores.

Nas camadas médias, viu-se o chamado "empreendimento forçado", que não é outra coisa que uma falsa empresarialização inicial, processo que acompanhou o desmantelamento do velho Estado empresário e, particularmente, seus antigos serviços sociais, questão que força a migração das velhas burocracias estatais. A isso segue-se, nos anos 1990, o surgimento não de uma condição independente própria daquelas "pequenas burguesias encarregadas dos negócios miúdos do capitalismo", mas sim de um assalariamento que se expande a novas camadas profissionais nos grandes holdings privados do crescimento econômico acelerado, ao ponto de configurar, na atualidade, uma burocracia moderna de serviços privados, que se constitui no grupo social mais numeroso da nova sociedade chilena. Enfim, a um mundo do trabalho profundamente perturbado somam-se setores médios muito diferentes dos da época anterior (Encina; Boccardo, 2014).

Se, nos inícios da experiência da refundação capitalista no Chile, observava-se o desmantelamento dos atores do antigo cenário social e, com isso, as bases de sustentação dos velhos projetos políticos e de desenvolvimento, no início do

1 Para uma análise mais detalhada dessa época, consultar Encina e Boccardo (2014). 
milênio, o novo panorama apresenta condições de maturidade. Seus problemas, como será visto mais adiante, também se distanciam de seus precedentes históricos, da mesma forma que sua especificidade merece consideração particular, a fim de compreender o sentido e as possibilidades da conflitualidade social recente.

\section{PRIVATIZAÇÃO DE SERVIÇOS SOCIAIS E CAPITALISMO DE SERVIÇO PÚBLICO COM SUBVENÇÃO ESTATAL}

Na experiência chilena, identificam-se dois ciclos de privatizações qualitativamente muito diferentes. Embora muito próximos no tempo, suas projeções sobre as condições de reprodução social resultam claramente distintos, assim como suas repercussões na vida cotidiana. São essas diferenças que tornam o caso chileno uma experiência peculiar de neoliberalismo avançado.

A primeira explosão de privatizações se estende sem novidade sobre as próteses desenvolvimentistas do velho "Estado empresarial". Em pouco tempo, por volta da metade dos anos 1970, as privatizações arrasaram com grande parte das empresas estatais que representavam algum interesse para as novas orientações financeiras e primário-exportadoras que advinham da virada neoliberal. Em paralelo, estruturaram-se novos grupos econômicos, nos quais se trançam alianças entre as velhas fortunas e os grupos de tecnocratas em ascensão, produzindo, de fato, um "novo mapa de riqueza extrema".

Nos anos 1980, não obstante, o afã privatizador se estende também de forma peculiar aos serviços sociais estatais. Esses últimos, previamente desmantelados e empobrecidos, vão experimentar uma abrupta guinada em direção a distintas modalidades da chamada "subsidiariedade social" e do consequente regime de "responsabilidade individual". Isso sucede de tal modo que, colocados nas mãos privadas, esses serviços passam a consolidar novos espaços de acumulação para os grupos econômicos emergentes. A falta de oposição política e social efetiva diante dessas novas privatizações - dada a desarticulação das antigas bases de ação coletiva, tanto por processos coercitivos quanto por processos de mudança estrutural - permitiu o avanço e a extensão da onda mercantil sobre o mundo de pensões, educação, saúde, moradia social, entre outras áreas emblemáticas dos velhos direitos e da proteção social. Nessa medida, ocorreu a constituição de enormes nichos de acumulação regulada sob os incentivos estatais que agora engrossam um gasto social orientado a subsidiar a demanda, no lugar da oferta pública desses serviços. Trata-se da criação de uma sorte de capitalismo de serviço 
público, em que a professada ideologia liberal se choca com o enorme subsídio estatal à ganância privada, do qual depende o cenário "liberal".

Seu avanço é distinto, conforme a área que abarca. Se as privatizações das pensões são feitas de forma abrupta e originam grandes massas de capital capazes de dinamizar, em pouco tempo, grande parte do auge da especulação financeira, na educação e na saúde, ao contrário, esse processo avança de forma gradual. Nesse sentido, a privatização da educação e da saúde percorre um caminho de mercantilização gradual e ininterrupto, até o início do novo milênio. Atravessa, assim, a transição para a democracia, momento no qual os conteúdos relativos ao modelo de desenvolvimento e à radical transformação capitalista herdada da ditadura estão, convenientemente, ausentes. Seu encerramento efetivo, em torno das dimensões procedimentais da reconstrução política institucional, permite excluir essas questões do debate público e, com isso, viabilizar sua naturalização e posterior expansão.

De tal sorte, nos anos 1990 e início dos anos 2000, semelhante expansão continua não mais sob a mão militar, senão com sobrenome "civil" e com legitimidade democrática. No Chile, o tristemente célebre Crédito con Aval del Estado (CAE) com que o Estado, na primeira década do novo milênio, dispôs-se a apoiar o ingresso dos jovens com menos recursos à educação superior privatizada e lucrativa - em forte conluio com a bancada privada - fez explodir protestos estudantis que colocam o Chile no foco da atenção internacional. Em linha similar, o chamado Plano Auge ${ }^{2}$ na saúde envolve enormes transferências de recursos estatais às clínicas privadas, as quais obtêm licitação para atender - de forma exclusiva ou, leia-se, monopolista - determinadas doenças. Trata-se de transferências de recursos estatais para provedores privados de serviços sociais que terminam por absorver grande parte dos aumentos orçamentários de gasto social, da transição para a democracia em diante, sob governos nominalmente socialistas, como os de Lagos (2000-2006) e de Bachelet (2006-2010).

Essas formas de acumulação privada com subsídio estatal que, em grande medida, explicam o crescimento de certos grupos econômicos chilenos, até alcançar escalas regionais inéditas, apegam-se a essa fórmula de subsídio à demanda, conhecida como "vouchers". Em definitivo, trata-se de uma acumulação rentista

2 Uma reforma do sistema de saúde implantada em meados da mesma década (2005), chamada Plan de Acceso Universal de Garantías Explícitas (AUGE), que concessiona determinadas doenças a centros privados de saúdes. Sustentada com recursos estatais que subsidiam a demanda, torna-se fonte principal da ganância e da expansão desses centros assistenciais privados, em uma forma cada vez mais contrastante com a decadência e a perda na cobertura dos serviços públicos de saúde. 
que agudiza a concentração da riqueza, de forma, aliás, pouco liberal; dinâmicas que nos anos recentes são acompanhadas de discursos do "empreendedorismo" e da "igualdade de oportunidades".

O mal-estar que acarreta esse panorama de ininterrupta expansão abarca, de forma evidente para amplas maiorias sociais, as condições mais cotidianas de reprodução social, dada sua aguda mercantilização no âmbito da evidente carência de qualquer tipo de proteção social, excluindo os grupos de extrema pobreza. Com isso, transferem-se para o indivíduo aumentos de incerteza e de perda da soberania de sua própria vida cotidiana, a ponto de envolver uma pressão extrema sobre os processos de individuação e os contextos sociais que os rodeiam.

Esse mal-estar terminou por se estender, também, às camadas médias, cujas aspirações de ascensão estavam ancoradas nas oportunidades que o crescimento acelerado do país parecia oferecer - um crescimento que, finalmente, se revelava como processo fortemente monopolizado por uma elite excludente. Tratava-se de uma frustração não apenas diante das incertezas de acesso a oportunidades de ascensão ou, pelo menos, de estabilidade, no âmbito da educação, mas, também, diante das próprias oportunidades de negócio, muito mais restritivas do que o sugerido pelo ideologismo da liberdade de empreendimento, com semelhante concentração de oportunidades. Disso resulta que, no final das contas, ao eliminar os velhos monopólios estatais, no interior desse processo histórico, as oportunidades comerciais que supostamente se abriam não eram destinadas a toda a sociedade (MONCKEBERG, 2001).

\section{O EXITOSO MATRIMÔNIO CHILENO ENTRE DEMOCRACIA E NEOLIBERALISMO}

Sem as pressões sociais que abundam em outras partes do continente, a transição para a democracia no Chile se destaca como uma das mais conservadoras da região. Sua atenção quase exclusiva aos aspectos da democratização política formal contrasta com o silêncio que cobre dimensões próprias da democratização social. O modelo de desenvolvimento herdado - os pilares da refundação capitalista - ficou fora do debate público que acompanhou esse processo.

A aguda desarticulação social herdada se converteu na base da chamada "governabilidade democrática" projetada para o futuro, o que significa, nos fatos, uma concepção da estabilidade democrática por intermédio de uma autonomização da esfera política em relação ao restante da sociedade. Tal restrição sobre as potencialidades representativas da política se expressa na então chamada "política dos acordos", na qual fluem os acordos entre as novas elites civis, os grupos 
empresariais e as garantias outorgadas ao recuo militar. A partir daí, tem-se uma transição para a democracia de caráter distintamente elitista, eminentemente procedimental, que se projeta sobre uma forte lacuna entre o social e o político ${ }^{3}$.

Trata-se de uma autonomização conservadora da política que se fundamenta, então, e com real efetividade, na desarticulação dos atores sociais clássicos da sociedade chilena, ou seja, na manifesta ausência, nos processos de transição à democracia e da consequente definição da futura dinâmica política, das velhas classes operárias e das camadas médias do período anterior. Disso deriva a calma característica do cenário social e político chileno dos anos 1990; é isso, mais do que uma suposta capacidade de controle social, associada de forma orgânica à Concertación - então no governo -, que cede certa politologia, fazendo abstrações da profunda transformação social que ocorria. Assim, recuperar uma compreensão social da política e, aliás, da economia, permite revisitar essas questões.

Claro, o Estado, que no fundamental mantém os marcos da reestruturação que sofreu, no que se refere às velhas orientações desenvolvimentistas, fomenta, hoje, a reprodução da desarticulação social subalterna que lhe fora legada. Um regime estrito de desrespeito estatal no que tange à regulação das relações sociais - especialmente as relações de trabalho - fomenta a despolitização das relações sociais situadas na base da sociedade. É um Estado que não promove formas de consenso e pacto social, senão que projeta a expulsão desses setores sociais subalternos dos processos de construção do Estado.

Os aspetos fundamentais do modelo de desenvolvimento herdado não só continuam como se aprofundam. Nos anos 1990, conforme dados oficiais, ao mesmo tempo em que a pobreza diminuiu, cresceu a desigualdade, colocando o Chile no horizonte dos países mais socialmente polarizados, não apenas do continente, mas de todo o mundo - e isso em pleno estágio de crescimento econômico ${ }^{4}$. Mesmo que seja certo dizer que "todos os barcos flutuam" com o crescimento, como prega o preceito monetarista, a experiência chilena dos anos 1990 revela claramente que uns barcos flutuam muitíssimo mais que outros. A concentração econômica aumentou até limites sem precedentes, enquanto os grandes grupos econômicos cresceram de tal modo que já avançam em uma agressiva expansão por todo o continente.

3 As preocupações despertadas nesse momento podem ser apreciadas nos escritos de intelectuais de relevância que tratam desse processo político e ideológico de ascensão de elites políticas civis: Faletto (1988) e Lechner (1989).

4 Para uma sistematização dessas estatísticas, consultar Carlos Ruiz Encina (2005). 
Os próprios nichos de acumulação regulada, sustentados por subsídios estatais, impulsionam esse extraordinário auge econômico, de cujas espetaculares taxas de crescimento, contudo, estão excluídas imensas camadas da sociedade, colocando, desse modo, as bases de um mal-estar que começa a crescer na primeira década do novo século, já livres do temor de um possível regresso autoritário, que tanto refreou o descontentamento no começo dos anos $1990^{5}$. Pode-se dizer, nesse sentido, que o celebrado "milagre chileno", que situou o país nas portas do desenvolvimento, já não é sentido da mesma maneira nos diferentes setores da sociedade, fato que começa a ser vislumbrado na conflitualidade social que posteriormente explodirá no país. Nesse processo, a refundação capitalista herdada termina por adotar um sobrenome civil sob esse progressismo neoliberal. Alinha-se, então, à resolução dos dilemas ideológicos que, em escala internacional, também adotaram Blair e Clinton, perante aspectos ideologicamente conservadores das heranças refundacionais que receberam, respectivamente, de Thatcher e Reagan.

Leva-se a cabo, assim, pelas mãos do ideologismo assentado nessas condições, um bem-sucedido casamento entre neoliberalismo e democracia de pelo menos quinze anos, que contrasta com a instabilidade social e política que, nesses mesmos anos, percorre o resto da região, nos esforços de ajustes estruturais, ao ponto de praticamente a metade dos governos civis democraticamente eleitos nos anos 1990 não conseguirem completar o mandato e serem depostos, em meio a agudas crises. O Chile aparecia como uma exceção política no cenário latino-americano dos anos 1990. No entanto, esse mesmo país incubava um mal-estar social que, na virada do século, não seria mais contido pelas estruturas políticas da transição.

\section{NOVOS CONFLITOS SOCIAIS E O TRANSBORDE DA POLÍTICA}

As margens da exposição especulativa dos fundos de pensões dirigidos por entes privados aumentam, de forma exponencial, sob a nova democracia, tanto nos pontos locais como nas bolsas internacionais. $\mathrm{O}$ crescimento do orçamento estatal para a saúde e a educação não implica, contudo, a restauração de alguma atenção pública a suas deterioradas estruturas, mas, ao contrário, traduzem-se apenas em maiores subsídios a ofertantes privados que obtêm concessão para oferecer esses "serviços sociais” à população. Em outras palavras, trata-se de uma demanda cativa, garantida pelo Estado, em que proliferam, em uma escala até

5 A aparente contradição entre esse mal-estar originário e o extraordinário crescimento econômico chileno é analisada em um estudo do PNUD (1998) desses anos, que causou grande impacto na discussão interna da Concertación. 
então desconhecida, as clínicas e os centros educacionais privados. O negócio da saúde e da educação, tanto como o das pensões, cresce de modo rentista, garantido pelo Estado. Trata-se, nessa medida, de um capitalismo de serviço público que começa a incubar um mal-estar crescente em uma população submetida a níveis extremos de individuação e privatização de suas condições de vida. A incerteza na vida cotidiana termina por explodir.

O problema mais visível, mas longe de ser o único, é o da educação. As promessas liberais da ascensão social vinculadas a ela, ou a simples expectativa de estabilidade nas posições sociais, vêm sendo frustradas nesse cenário para extensas camadas da população. O movimento estudantil é quem captura de modo mais visível esse descontentamento.

Em 2006, são os estudantes secundaristas que agitam o país, produzindo a maior mobilização do período democrático. Naquele momento, impressionou o enorme e heterogêneo apoio social recebido, aliás, inédito nos anos de democracia: desde os setores populares, mais tradicionalmente descontentes, até camadas médias tidas como acomodadas ou recém-chegadas a essa condição no recente auge econômico. De toda a forma, é o anúncio de um novo contexto para a pouco participativa "governabilidade democrática" da transição. Contudo, nessa ocasião, o primeiro governo de Bachelet não escutou a sociedade e liderou um pacto elitista com a direita, no qual a política passou a se refugiar em "especialistas", mediante uma saída tecnocrática. Pior ainda, impulsionou novas levas de orçamento estatais para subsidiar a expansão desatada da educação superior privada, por meio do já mencionado Crédito con Aval del Estado (CAE).

Contudo, as coisas não demoraram novamente a explodir. O CAE se encontra, precisamente, no centro do furacão que volta a explodir, em maior escala, em 2011, ano do retorno das manifestações estudantis contra o lucro desenfreado na educação. Se, em 2006, o protesto dos estudantes secundários fora acompanhado por outros conflitos, especialmente entre grupos de trabalhadores subcontratados, dessa vez, em 2011, explodiram conflitos regionais variados, ambientais, de movimentos feministas, pelas liberdades sexuais, entre tantos outros.

Nesse ano, é notável que ao tradicional protesto dos estudantes das universidades estatais, ineditamente e de forma massiva, somam-se os centros universitários privados que proliferaram nas últimas décadas. Associados a um imaginário de "nova classe média" - devido à sua origem em diferentes setores populares -, esses futuros profissionais se somaram às marchas e greves, passando de dezenas de milhares a centenas de milhares. Não obstante, embora a educação continue sendo o problema mais visível e que desperta o maior consenso na socie- 
dade, a miríade de outros temas e os conseguintes processos de constituição de movimentos e atores sociais que eles abrigam oferecem, de forma contundente, um novo cenário social no Chile, que não demora a impactar os limites políticos de uma democracia concebida conservadoramente na transição ${ }^{6}$.

Trata-se, então, do transbordamento da política. Uma institucionalidade política, concebida a partir da desarticulação dos atores sociais tradicionais e seus problemas, não está preparada para se encarregar da maturação de novos atores sociais, precisamente, filhos da modernização capitalista das últimas décadas. Os problemas desses últimos, assim como suas formas de ação e suas identidades, diferem dos padrões clássicos e, com isso, deixam desconcertados os modos de controle e domínio social. A política, antes surda diante da sociedade, agora parece muda.

Os modos de controle e domínio social da experiência democrática têm apostado na naturalização da aguda restrição de direitos sociais universais herdada da ditadura. Isso em nome de uma democratização política formal, carente de atores sociais subalternos de alguma relevância; uma aposta que funcionou sobre as ruínas da velha estrutura social, mas não frente ao amadurecimento de um novo cenário social produzido, justamente, por essas mudanças e pela refundação capitalista.

A assim concebida democratização política não apostou na promoção do agrupamento de interesses e na participação institucional como processos que conduzissem à formação de pactos e consensos sociais. Logo, a formação da ação social subalterna não teve, então, outra opção senão correr pelos trilhos externos a essa institucionalidade democrática restrita e elitista. Observou-se, desse modo, um curso de autonomização forçada desses processos sociais subalternos de constituição de novos atores e movimentos.

Nesse sentido, o amadurecimento de novas frações sociais próprias da refundação capitalista desata uma crise de representação política, com demandas diferentes das clássicas, colocando no centro uma controvérsia sobre a privatização extrema da reprodução social. Trata-se das novas camadas médias, muito amplas e heterogêneas, filhas do crescimento econômico desregulamentado. São os novos assalariados, os trabalhadores subcontratados, filhos da "externalização de funções" das grandes empresas, que expulsam para pequenas unidades precárias “independentes” muitos dos antigos postos de trabalho estáveis. Essas novas

6 Para uma análise mais extensa sobre esse proceso de transformações sociais, as opiniões dos atores e as mudanças institucionais, consultar o artigo de Carlos Ruiz Encina (2013). 
camadas não repetem os velhos marcos identitários. Não são aquelas associações profissionais desenvolvimentistas, tampouco o velho movimento operário sindicalizado em organizações tradicionais. Não repetem, também, os velhos padrões de ação social e de politização, nem a clivagem democracia versus ditadura, nem esquerda versus direita, em suas conotações históricas. Explicam, em suficiente medida - à diferença de seus antecessores -, os processos de formação desses atores sociais; e tal explicação está, ao contrário, nas contradições do neoliberalismo avançado da experiência chilena.

No transbordamento da política institucional, terminam por exceder, também, os marcos da cultura política daqueles grupos: os fatores fundamentais sob os quais se erguia aquela cultura política, profundamente manipulados pelo progressismo neoliberal dos governos civis nas últimas décadas - como a clivagem ditadura-democracia e a forma artificial com que se desenhava a polaridade esquerda-direita -, perderam sentido para as novas forças sociais.

De tal forma, se a negociação e o pacto da transição entre a Concertación e o pinochetismo se fundamentou na desarticulação social subalterna herdada tanto da repressão quanto da transformação estrutural -, o discurso ideológico que acompanhou esse processo de democratização, somado à própria polaridade ditadura-democracia, foi o velho discurso que opõe Estado e Mercado, como forma de recuperação da chamada "dívida social”, produto da desigualdade crescente durante o regime autoritário. No entanto, a própria projeção do modelo de crescimento herdado e o aprofundamento das condições de mercantilização da vida cotidiana fazem com que o Estado não seja mais avaliado pela população como algo oposto ao mercado, como se sucedia, de fato, nos velhos ideários, mas sim como um apoio desse último. De modo que tal "contradição" expressa nos códigos da velha cultura política perde sentido para os novos setores sociais, cujas condições de reprodução social privatizadas não se alteraram, e até se aguçaram, com os subsídios estatais ao lucro privado desse capitalismo de serviços públicos.

A contraposição entre Estado e mercado, como marco identitário da produção de ação social e da constituição de atores, é ultrapassada por outra que opõe a democracia à dita expansão mercantil desenfreada - com amparo estatal - da vida cotidiana. Com isso, as demandas econômicas concretas dos movimentos atuais adquirem uma conotação pública diferente daquelas próprias da política institucional, concebida no processo de transição para a democracia.

Para a democracia vigente - sob os acordos políticos -, não era uma preocupação incorporar os novos segmentos sociais. Sua dimensão mínima e sua heterogeneidade, no momento dos pactos de transição, tornaram possível o cálculo 
de sua exclusão. Todavia, diante da surdez e da reticência elitista dos marcos políticos vigentes, a maturação desses setores sociais termina por ultrapassar os limites da transição para a democracia. Constituem-se, então, em uma pressão para reconstruir a política e, com isso, abrem a possibilidade de um novo ciclo histórico.

Esse não é, certamente, um processo consolidado. Ainda são contundentes as resistências dos grupos que apelam para os marcos conservadores da transição, porém essa possibilidade parece cada vez mais aberta; uma possibilidade que resultava difícil de se antever pela calma chilena dos anos 1990, calmaria que inspirava outras conjecturas de certa politologia, mais interessada nas capacidades de controle social da Concertación.

Hoje, esses setores sociais, filhos da modernização radical capitalista da história chilena mais recente, transitam aceleradamente em busca de seus próprios termos de constituição política e de articulação de um projeto de certa historicidade; um projeto que já tem como eixo inicial o enfrentamento ao Estado subsidiário, herdado da experiência ditatorial e, com isso, a correspondente luta pelos direitos sociais, mediante desmercantilização das chaves atuais extremas da reprodução da vida cotidiana. É um marco ainda muito geral, mas que, nas condições chilenas, resulta muito tangível e vinculado à vida cotidiana concreta.

\section{REFERÊNCIAS BIBLIOGRÁFICAS}

Encina, Carlos Ruiz. ¿Habrá crecimiento con igualdad hacia el bicentenario?, Revista Análisis del año 2004. Política, Sociedad y economía, Departamento de Sociología, Universidad de Chile, Santiago, 2005.

Conflicto social en el neoliberalismo avanzado: análisis de clase de la revuelta estudiantil en Chile. Buenos Aires: Clacso, 2013.

Progresismo neoliberal, democracia y refundación capitalista en América Latina. Revista Estudios Latinoamericanos del CELA, 2015, no prelo.

Encina, Carlos Ruiz; Boccardo, Giorgio. Los chilenos bajo el neoliberalismo: clases y conflicto social. Santiago: El Desconcierto - Fundación Nodo XXI, 2014.

Faletto, Enzo. La especificidad del Estado latino-americano. Revista de la CEPAL, Santiago, n. 38, 1988.

LECHNER, Norbert. Los patios interiores de la democracia. Santiago: FCE, 1989.

Monckeberg, M. O. El saqueo de los grupos económicos al Estado chileno. Santiago: Ediciones B, 2001.

PNud. Las paradojas de la modernización. Santiago, 1998.

WEFFort, Francisco. Clases populares y desarrollo social. Santiago: ILPES, 1968. 